\title{
Co-movement in crypto-currency markets: evidences from wavelet analysis
}

\author{
Anoop S Kumar ${ }^{1}$ and Taufeeq Ajaz ${ }^{2 *}$ (D)
}

\author{
* Correspondence: tajazgeight@ \\ gmail.com \\ ${ }^{2}$ School of Economics, Narsee \\ Monjee Institute of Management \\ Studies, Bangalore, Karnataka \\ 560083, India \\ Full list of author information is \\ available at the end of the article
}

\begin{abstract}
We study the time varying co-movement patterns of the crypto-currency prices with the help of wavelet-based methods; employing daily bilateral exchange rate of four major crypto-currencies namely Bitcoin, Ethereum, Lite and Dashcoin. First, we identify Bitcoin as potential market leader using Wavelet multiple correlation and Cross correlation. Further, Wavelet Local Multiple Correlation for the given cryptocurrency prices are estimated across different time-scales. From the results, it is found that that the correlation follows an aperiodic cyclical nature, and the crypto-currency prices are driven by Bitcoin price movements. Based on the results obtained, we suggest that constructing a portfolio based on crypto-currencies may be risky at this point of time as the other crypto-currency prices are mainly driven by Bitcoin prices, and any shocks in the latter is immediately transformed to the former.
\end{abstract}

Keywords: Bitcoin, Co-movement, Crypto-currencies, Wavelets

JEL classification: G10, G11

\section{Introduction}

Crypto-currencies are the latest addition to the financial instruments, and the ones garnering increased attention during the recent times (Urquhart 2018). The first asset of this class was Bitcoin, launched in 2009 immediately after the 2008 financial crisis. In the initial days, people seemed skeptic about this new product. However, in the last couple of years, there has been an exponential increase in the demand of Bitcoin, and the market has witnessed a huge growth in terms of both market capitalization and introduction of new crypto-currency assets. The number of crypto-currencies has increased from 500 in 2014 (White 2015) to 1560 currencies as on 8 April 2018. The increased market capitalization as well as introduction of new asset points resulted in market becoming more liquid and investors being active. However, irrespective of this upward momentum, there are serious concerns raised about various dimensions of crypto-currency markets.

The high volatility exhibited by the crypto-currency market is a pressing concern. Compared to traditional financial markets, crypto-currency markets are shallow (Bohme et al. 2015); in such a market, any shocks or fluctuation in the market leader may easily transfer and trigger a market collapse. Further, the crypto-currency market, unlike traditional financial markets, has possible unequal distribution of assets. The

(C) The Author(s). 2019 Open Access This article is distributed under the terms of the Creative Commons Attribution 4.0 International License (http://creativecommons.org/licenses/by/4.0/), which permits unrestricted use, distribution, and reproduction in any medium, provided you give appropriate credit to the original author(s) and the source, provide a link to the Creative Commons license, and indicate if changes were made. 
first-generation miners and investors had relative ease to mine and purchase cryptoassets (Smith and Kumar 2018). With this, there is possibility of engineering price movements. Gandal et al. (2018) shows evidence towards such a suspicious trading activity in Mt. Gox exchange in 2013.

The other dimension being the use of crypto-currencies. Apart from gambling, online gaming, possible money laundering (Moser et.al. 2013) and cross-border transactions, speculation is one of the important motivations associated with crypto-currencies (Smith and Kumar 2018). Glaser et al. (2014) argues that utility for crypto assets stems from their appeal as an asset class. Similar argument is put forward by Baur et al. (2018) based on their analysis of transaction value and frequency in Blockchain.

With crypto-currencies being integrated with the traditional financial assets (see, Tony et al. 2018; Khaled et al. 2018 and Henriques and Sadorsky 2018), there is bound to be more investor attention and the possibility of market being more liquid. In such a scenario, exploring the potential for diversification in crypto-currency markets is of paramount importance. However, the existing research on this phenomenon is sparse. Our paper addresses this issue.

Remainder of this article is structured as follows: Section 2 provides a brief review of literature, section 3 discusses data and methodology employed. Section 4 shows the estimation results and its explanation while section 5 provides the concluding remarks.

\section{Literature review}

The majority of research in crypto-currency markets can be categorized into: a) price determination and value formation (Urquhart 2017; Van Alstyne 2014; Yermack 2013; Ali et al. 2014; Glaser et al. 2014; Kristoufek 2015; Baek and Elbeck 2015; Ciaian et al. 2016; Bouoiyour et al. 2016; Blau 2017; Zhu et al. 2017), b) volatility (Katsiampa 2017; Jiang et al. 2017; Dwyer 2015; Bouoiyour and Selmi 2016; Dyhrberg 2016), c) speculative bubbles (Cheah and Fry 2015; Cheung et al. 2015; Godsiff 2015; Fry and Cheah 2016; Urquhart 2016; Nadarajah and Chu 2017) and d) forecasting and prediction of cryptocurrencies using different models (Hotz-Behofsits et al. 2018; Catania et al. 2019).

There exist a number of studies that discuss the co-movement of Bitcoin and other financial instruments. Evidences supporting cointegration of Bitcoin exchange rates with conventional exchange rates is found in Chu et al. 2015. Pieters and Vivanco (2017) study cointegration among various Bitcoin exchange prices and finds that Bitcoin doesn't follow the law of one price. In a similar study, Dirican and Canoz (2017) find evidences that support long run co-movements between Bitcoin and major stock indices. Salman and Razzaq (2018) study the cointegration between Bitcoin prices and its determining factors using Johansen's cointegration method and find supportive evidence towards cointegration. In a recent study, Ciaian and Rajcaniova (2018) implemented ARDL (Auto Regressive distributed lag model) $m$ ethodology and found that Bitcoin price movement and other crypto-currency price movements are independent of each other.

From the literature it is evident that barring a few studies (Bohme et al. 2015; Narayanan et al. 2016; Smith and Kumar 2018) there is lack of a comprehensive research that addresses the dynamics of crypto-currency market in its isolation. With crypto-currency market evolving as independent market segment, a study of crypto-currency market dynamics in its isolation will be of immense use to both researcher and investors. Our work aims to fill this gap and attempts to address this issue in a detailed manner. We study 
the co-movement of four major crypto-currencies during the last 3 years, during which the crypto-currency market started becoming more liquid. Considering the fact that cryptocurrency markets might be populated by investors with different time horizons (DelfinVidal and Romero-Meléndez 2016); we forego the traditional time series methods and adapt a comprehensive wavelet-based methodology. Wavelets are preferred due to their ability to extract information from time series at various without losing its timescale dimension. Rationale behind choosing wavelet based analysis is provided in the methodology section.

First, we identify the potential market leader using wavelet multiple correlation and wavelet multiple cross-correlation. After this, we estimate evolution of local dynamics by estimating wavelet local multiple correlation for the four crypto-currencies under study and see if the dynamics of multiple correlation structure can be explained by the price movement of the potential market leader.

\section{Data and methodology}

We use daily prices (in US Dollar) of four major crypto-currencies namely Bitcoin, Ethereum, Lite and Dashcoin from 7 August, 2015 to 24 March, 2018 for our analytical purpose. We select these four majors crypto-currencies as they represent a fair share of the market in terms of market capitalization. Further, we select six random crypto currencies namely Reddcoin, DigixDao, Luckycoin, Bitmark, Edgecoin and Unobatanium for comparison purposes. The data is collected from coinmarketcap.com, a cryptocurrency data aggregation website. There were no missing values.

Here, a wavelet-based methodology is applied to study the time-varying nature of comovements in the crypto-currency markets across different scales. We are only looking at the short to medium term dynamics, as the crypto-currency market is still its nascent stage.

While the standard time series/frequency domain tests can provide information about the possible presence of co-movement among a multivariate time series, these tests have some serious limitations. First, while they can identify the presence of long run co-movement and short-term adjustment, these tests fail to provide a statistic that could quantify the extent of co-movement. Considering the fact that there are agents with different trading time horizons operating in financial markets (Delfin-Vidal and Romero-Meléndez 2016), it is possible that the nature of relationship between these markets vary across different timescales. The traditional time series measures can provide measures only at the given frequency. Wavelet methods are employed to extract information across various frequencies without losing the time dimension.

Wavelet Multiple Correlation (WMC henceforth) measure, proposed by Macho (2012) can overcome these two shortcomings. The Wavelet multiple correlation coefficient measure could provide the strength of co-movement among a multivariate time series across different timescales, so that one could distinguish between the short run, medium run and long run relationship. Similarly, Macho proposes Wavelet Multiple Cross Correlation (WMCC henceforth) in the same article. WMCC provides a measure to identify a potential leader among the group, that could influence the other variables present in the group.

These measures are better compared to the traditional wavelet correlation and cross correlation measures in terms of parsimony. If we have 5 markets, then we would have to calculate $\mathrm{nX}(\mathrm{n}-1) / 2=10$ wavelet correlation plots and $\mathrm{J}$ (order of wavelet decomposition) 
times wavelet cross correlation plots, resulting in a cumbersome process. If we employ WMC and WMCC methods, we need to only plot J correlation plots and J crosscorrelation plots.

Further in a multivariate context, a pair-wise correlation coefficient could be spurious due to possible relationship of one variable with other variables. WMC and WMCC estimates overall correlations within the multivariate framework across different time scales making interpretation of the results easier.

Wavelet Local Multiple Correlation (WMLC henceforth), proposed by FernándezMacho (2018) is an extension Macho (2012). While WMC and WMCC provided an overall measure of correlation across in a multivariate context, WLMC provides a local measure of the same so that one could study the evolution of wavelet multiple correlation values over time. First, we will briefly explain the WMC and WMCC estimation. In the next step, a detailed explanation of WLMC estimation will be given.

The wavelet Multiple correlation is explained as follows:

Let $\left\{\mathrm{X}_{\mathrm{t}}\right\}$ be a multivariate stochastic process and let $\left\{\mathrm{W}_{\mathrm{jt}}\right\}$ be the respective $\mathrm{j}^{\text {th }}$ level wavelet coefficients obtained by the application of maximal overlap discrete wavelet transform (MODWT). The wavelet multiple correlation (WMC) $\varnothing x\left(\lambda_{j}\right)$ can be defined as one single set of multi scale correlations calculated from $X_{t}$ as follows.

At each wavelet scale $\lambda_{j}$ we calculate the square root of the regression coefficient of determination in that linear combination of variables $w_{i j t}, i=1,2, \ldots n$, for which the coefficient of determination is a maximum. The coefficient of determination corresponding to the regression of a variable $Z_{\mathrm{i}}$ on a set of regressors $\left\{Z_{\mathrm{k}}, \mathrm{k} \neq \mathrm{i}\right\}$, could be obtained as $\mathrm{R}_{\mathrm{i}}^{2}=1-1 / \rho^{i i}$, where $\rho^{i i}$ is the $\mathrm{i}^{\text {th }}$ diagonal element of the inverse of the complete correlation matrix $\mathrm{P}$.

The WMC, $\varnothing x\left(\lambda_{j}\right)$ is obtained as

$$
\phi_{X}\left(\lambda_{j}\right)=\sqrt{1-\frac{1}{\max \operatorname{diag} P_{j}^{-1}}}
$$

Where $\mathrm{P}$ is the $\mathrm{N} \times \mathrm{N}$ correlation matrix of $\mathrm{W}_{\mathrm{jt}}$, and the max $\operatorname{diag}($.$) operator selects$ the largest element in the diagonal of the argument. Since the $R_{i}^{2}$ coefficient can be shown equal to the square of the correlation between the observed values of $z_{i}$ and the fitted values $z_{i}$ obtained from such a regression (see Appendix), $\varnothing x(\lambda j)$ can also be expressed as:

$$
\begin{gathered}
\phi_{X}\left(\lambda_{j}\right)=\operatorname{Corr}\left(\omega_{i j t}, \hat{w}_{i j t}\right) \\
=\frac{\operatorname{Cov}\left(\omega_{i j t}, \hat{w}_{i j t}\right)}{\sqrt{\operatorname{Var}\left(\omega_{i j t}\right)} \sqrt{\operatorname{Var}\left(\hat{w}_{i j t}\right)}}
\end{gathered}
$$

Where the wavelet variances and covariance are defined as follows:

$$
\begin{aligned}
& \operatorname{Var}\left(w_{i j t}\right)=\frac{1}{T_{j}} \sum_{t=j-1}^{T-1} w_{i j t}^{2} \\
& \operatorname{Var}\left(\hat{w}_{i j t}\right)=\frac{1}{T_{j}} \sum_{t=j-1}^{T-1} \hat{w}_{i j t}^{2}
\end{aligned}
$$




$$
\operatorname{Cov}\left(\omega_{i j t}, \hat{w}_{i j t}\right)=\frac{1}{T_{j}} \sum_{t=L_{j}-1}^{T-1} \omega_{i j t} \hat{w}_{i j t}
$$

Where $\mathrm{w}_{\mathrm{ij}}$ on a set of regressors $\left\{\mathrm{w}_{\mathrm{kj}}, \mathrm{k} \neq \mathrm{i}\right\}$, leads to the maximization of the coefficient of determination, $\hat{w}_{i j}$ represents the fitted values. The number of wavelet coefficients affected by boundary associated with a wavelet filter of length $\mathrm{L}$ and scale $\lambda_{j}$ is calculated as

$L_{j}=\left(2^{j}-1\right)(L-1)+1$. Then the number of wavelet coefficients unaffected by the boundary conditions is obtained as $\tilde{T}_{j}=T-L_{j}-1$.

Allowing a lag $\tau$ between observed and fitted values of the variables selected as the criterion variable at each scale $\lambda_{j}$, we may define the wavelet multiple cross correlation (WMCC henceforth) as

$$
\begin{aligned}
& \phi_{X, \tau}\left(\lambda_{j}\right)=\operatorname{Corr}\left(\omega_{i j t}, \hat{w}_{i j t+\tau}\right) \\
& =\frac{\operatorname{Cov}\left(\omega_{i j t}, \hat{w}_{i j t+\tau}\right)}{\sqrt{\operatorname{Var}\left(\omega_{i j t}\right)} \sqrt{\operatorname{Var}\left(\hat{w}_{i j t+\tau}\right)}}
\end{aligned}
$$

For $n=2$ the WMC and WMCC are the same as the standard wavelet correlation and cross correlation.

However, as the WMC and WMCC could not explain the evolution of potential local non-linear dynamics, Macho (2018) proposed WMLC (Wavelet Multiple Local Correlation) as an extension as the WMC method. The method is described as follows.

Let $X$ be the multivariate time series under consideration and let $W_{j t}=\left(w_{1 j t}, w_{2 j t} \ldots\right.$ $\ldots . w_{n t}$ ) be the $\lambda_{j}$ wavelet coefficients obtained by applying an MODWT on all $x \in X$. Following Macho (2012), at each wavelet scale $\lambda_{j}$ we calculate the square root of the regression coefficient of determination in that linear combination of variables $\mathrm{w}_{\mathrm{ijt}}, \mathrm{i}=1$, $2, \ldots \mathrm{n}$, for which the coefficient of determination is a maximum. The coefficient of determination corresponding to the regression of a variable $Z_{i}$ on a set of regressors $\left\{Z_{\mathrm{k}}, \mathrm{k} \neq \mathrm{i}\right\}$, could be obtained as $\mathrm{R}_{\mathrm{i}}^{2}=1-1 / \rho^{i i}$, where $\rho^{i i}$ is the $\mathrm{i}^{\text {th }}$ diagonal element of the inverse of the complete correlation matrix P. $\Phi_{X S}\left(\lambda_{j}\right)$ is obtained as

$$
\phi_{X, s}\left(\lambda_{j}\right)=\sqrt{1-\frac{1}{\max \operatorname{diag} P_{j, s}^{-1}}}
$$

Where $P_{j, s}$ is the $\mathrm{n} \mathrm{X} \mathrm{n}$ weighted correlation matrix of $\mathrm{W}_{\mathrm{jt}}$, with weights $\theta(t-s)$ and the $\max \operatorname{diag}($.$) operator selects the largest element in the diagonal of the argument.$ Since the $R^{2}{ }_{i}$ coefficient can be shown equal to the square of the correlation between the observed values of $Z_{i}$ and the fitted values $Z_{i}$ obtained from such a regression, $\Phi_{X, s}\left(\lambda_{j}\right)$ can also be expressed as:

$$
\begin{gathered}
\phi_{X, s}\left(\lambda_{j}\right)=\operatorname{Corr}\left(\theta(t-s)^{1 / 2} \omega_{i j t}, \theta(t-s)^{1 / 2} w_{i j t}\right) \\
=\frac{\operatorname{Cov}\left(\theta(t-s)^{1 / 2} \omega_{i j t}, \theta(t-s)^{1 / 2} \hat{w}_{i j t}\right)}{\sqrt{\operatorname{Var}\left(\theta(t-s)^{1 / 2} \omega_{i j t}\right)} \sqrt{\operatorname{Var}\left(\theta(t-s)^{1 / 2} \hat{w}_{i j t}\right)}} \quad \text { for } \mathrm{s}=1,2 \ldots \mathrm{T}
\end{gathered}
$$


Where the $w_{i j}$ is chosen to maximize $\phi_{X, s}\left(\lambda_{j}\right)$. Applying MODWT to the given multivariate timeseries $\mathrm{X}$ for an order $\mathrm{J}$, we can obtain $\mathrm{J}$ number of $\mathrm{T}$ length MODWT coefficients,

$\widetilde{W_{J}}=\left\{\widetilde{W_{j 0}}, \widetilde{W_{J 1}}, \ldots \ldots \ldots \widetilde{W}_{\text {J,T-1 }}\right\}$. From Eq. (1), the WLMC of scale $\lambda_{j}$ is a non-linear function of all the $\mathrm{n}(\mathrm{n}-1) / 2$ weighted correlations of $W_{j t}$. Alternatively, it could be explained in terms of all the weighted variances and covariances of $W_{j t}$, as shown in Eq. (2). Hence, a consistent estimator of WLMC based on MODWT could be derived as:

$$
\begin{gathered}
\tilde{\phi}_{X, s}\left(\lambda_{j}\right)=\sqrt{1-\frac{1}{\max \operatorname{diag} \tilde{P}_{j, s}^{-1}}} \\
=\frac{\operatorname{Cov}\left(\theta(t-s)^{1 / 2} \tilde{w}_{i j t}, \theta(t-s)^{1 / 2} \tilde{\tilde{w}}_{i j t}\right)}{\sqrt{\operatorname{Var}\left(\theta(t-s)^{1 / 2} \tilde{w}_{i j t}\right)} \sqrt{\operatorname{Var}\left(\theta(t-s)^{1 / 2} \widehat{\tilde{w}}_{i j t}\right)}}
\end{gathered}
$$

Where the weighted wavelet variances and covariances can be estimated as:

$$
\begin{gathered}
\operatorname{Var}\left(\tilde{w}_{i j t}\right)=\frac{1}{T_{j}} \sum_{t=L_{j}-1}^{T-1} \theta(t-s) \tilde{w}_{i j t}^{2} \text { for } \mathrm{s}=1,2 \ldots . \widehat{T} . \\
\operatorname{Var}\left(\widehat{\tilde{w}}_{i j t}\right)=\frac{1}{T_{j}} \sum_{t=j-1}^{T-1} \widehat{\tilde{w}}^{2}{ }_{i j t} \text { for } \mathrm{s}=1,2 \ldots \ldots \hat{T} \\
\operatorname{Cov}\left(w_{i j t}, \widehat{\tilde{\tilde{w}}}_{i j t}\right)=\frac{1}{T_{j}} \sum_{t=L_{j}-1}^{T-1} \theta(t-s) \tilde{w}_{i j t} \widehat{\tilde{\tilde{w}}}_{i j t} \text { for } \mathrm{s}=1,2 \ldots \ldots \hat{T}
\end{gathered}
$$

$\tilde{w}_{i j}$ is selected such that regressing $\tilde{w}_{i j}$ on a set of regressors $\left\{\tilde{w}_{k j}, \mathrm{k} \neq \mathrm{i}\right\}$ leads to the maximization of the coefficient of determination, $\widehat{\tilde{w}}_{i j}$ represents the fitted values. The number of wavelet coefficients affected by boundary associated with a wavelet filter of length $\mathrm{L}$ and scale $\lambda_{j}$ is calculated as $\mathrm{L}_{j}=\left(2^{\mathrm{j}}-1\right)(\mathrm{L}-1)+1$. Then the number of wavelet coefficients unaffected by the boundary conditions is obtained as $\tilde{T}_{j}=T-L_{j}-1$.

Macho (2012) constructs the confidence intervals using the Fisher's transform. Fisher's transformation is defined as $\operatorname{arctanh}(\mathrm{r})$; where $\operatorname{arctanh}($.$) is the inverse hyperbolic$ tangent function, and $r$ is the sample correlation value. and it is used to construct confidence interval for a population correlation is based on the fact that if $(\mathrm{X}, \mathrm{Y})$ follows a bivariate normal distribution with $\rho=\operatorname{Corr}(\mathrm{X}, \mathrm{Y})$, then the transformed sample correlation coefficient calculated from $\mathrm{T}$ independent pairs of observations can be shown to be approximately normally distributed with mean $\operatorname{arctanh}(\mathrm{r})$ and variance $(T-3)^{-1}$. (Fisher 1922). Here, confidence intervals are estimated applying this method to the sample wavelet local multiple correlation coefficient $\tilde{\phi}_{X, s}\left(\lambda_{j}\right)$ as follows:

Let $\left\{\mathrm{X}_{\mathrm{t}}\right\}$ be a realization of multivariate Gaussian stochastic process and let $\tilde{W}_{j}=\left(\tilde{W}_{j 0} \ldots \tilde{W}_{j, T-1}\right)=\left\{\left(\tilde{w}_{1 j 0} \ldots \tilde{w}_{n j 0}\right),\left(\tilde{w}_{1 j, T / 2^{j}-1}\right)\right\}, \mathbf{j}=1,2 \ldots \ldots .$. , be vectors of wavelet coefficients obtained by applying a MODWT of order $J$ to each of the univariate time series $\left(x_{i 1}, x_{i 2}, \ldots . x_{i T}\right)$ for $\mathrm{i}=1,2 \ldots$. If $\tilde{\phi}_{X, j}\left(\lambda_{j}\right)$ is the sample wavelet multiple local correlation obtained from Eq (1), then $\tilde{z}_{j} \sim F N\left(z_{j},\left(T / 2^{j}-3\right)^{-1}\right)$, Where $z_{j}=\arctan$ $h\left(\varnothing_{X s}\left(\lambda_{j}\right)\right), \tilde{z}_{j}=\arctan h\left(\tilde{\phi}_{X, s}\left(\lambda_{j}\right)\right)$ and FN stands for Folded Normal Distribution. 
The 100 $(1-\alpha) \%$ confidence interval for the true value of $\phi_{X,}\left(\lambda_{j}\right)$ is then obtained as $C I_{1-\alpha}\left(\phi_{X, \tau}\left(\lambda_{j}\right)\right)=\tanh \left(\tilde{z}_{j}-c_{2} / \sqrt{T / 2^{j}-3} ; \tilde{z}_{j}+c_{1} / \sqrt{T / 2^{j}-3}\right)$ where $c_{1}$ and $c_{2}$ are folded normal critical values.

We select a Gaussian window with length $M=N / 2^{\wedge} 4$, as suggested by FernándezMacho (2018).

\section{Results and discussion}

Before we start the wavelet analysis, we want to see if there exist any long run cointegration among the variables of interest. Towards this, we apply Johansen (1992) cointegration test on the four crypto-currency prices. Result of the same is provided in Table 1. From the results, it can be seen that there is a cointegrating relationship between the cryptocurrencies under analysis and we proceed towards the wavelet analysis (Fig. 1).

First, we want to see if we can establish Bitcoin as a potential market leader. Towards this, we employ Wavelet Multiple Correlation (WMC) and Wavelet Multiple Cross Correlation (WMCC) and obtain the results for the overall period of analysis. The estimations are carried out from scales 2-4 days (intra-week scale) to 16-32 days (monthly scale). The results are shown in Figs. 2 and 3.

Here, we see that the market is moderately correlated during the period of analysis. And at each scale, the crypto-currency that maximizes the correlation value is against the linear combination of the other crypto-assets are shown in the plot. At all the 4 scales, bitcoin is the one that found to be maximizing WMC, indicating Bitcoin as a potential leader/follower. Next, we try to confirm this fact by estimating Wavelet Multiple Cross Correlation at a lead/lag of 36 days. The results are shown in Fig. 2.

The cross-correlation Plot explains the potential lead-lag relationship between the crypto-currency prices. Here, the crypto-currency that maximizes the multiple correlation value against the linear combination of the other currencies is shown at top-let corner in each scale plot for all the scales. We can see that Bitcoin maximizes WMC against the other currencies across all scales. However, as the highest value of WMCC is obtained at lag zero, we cannot conclude solely based on the test results whether Bitcoin leads ahead or lags behind other crypto-currencies. However, with Bitcoin accounting for the largest market capitalization in the crypto-currency market, it would be safe to assume that Bitcoin is the market leader in crypto-currency markets. As WMCC identifies Bitcoin as potential leader/follower, our assumption is not solely based on simple observation, but backed up by statistical evidences.

The next step in the analysis will be to obtain a detailed timeline on major price fluctuations in the market leader. Details about major events in Bitcoin prices are

Table 1 Cointegrating relationship between the Cryptocurrencies

\begin{tabular}{lllll}
\hline Unrestricted Cointegration Rank Test (Maximum Eigenvalue) & & \\
\hline Hypothesized No. of CE(s) & Eigenvalue & Max-Eigen Statistic & 0.05 Critical Value & Prob. $^{{ }^{2}}$ \\
\hline None $^{\mathrm{a}}$ & 0.034127 & 33.19537 & 32.11832 & 0.0368 \\
At most 1 & 0.014041 & 13.51833 & 25.82321 & 0.7628 \\
At most 2 & 0.006314 & 6.055783 & 19.38704 & 0.9534 \\
At most 3 & 0.005106 & 4.893530 & 12.51798 & 0.6117 \\
\hline
\end{tabular}

Max-eigenvalue test indicates 1 cointegrating eqn(s) at the 0.05 level adenotes rejection of the hypothesis at the 0.05 level 


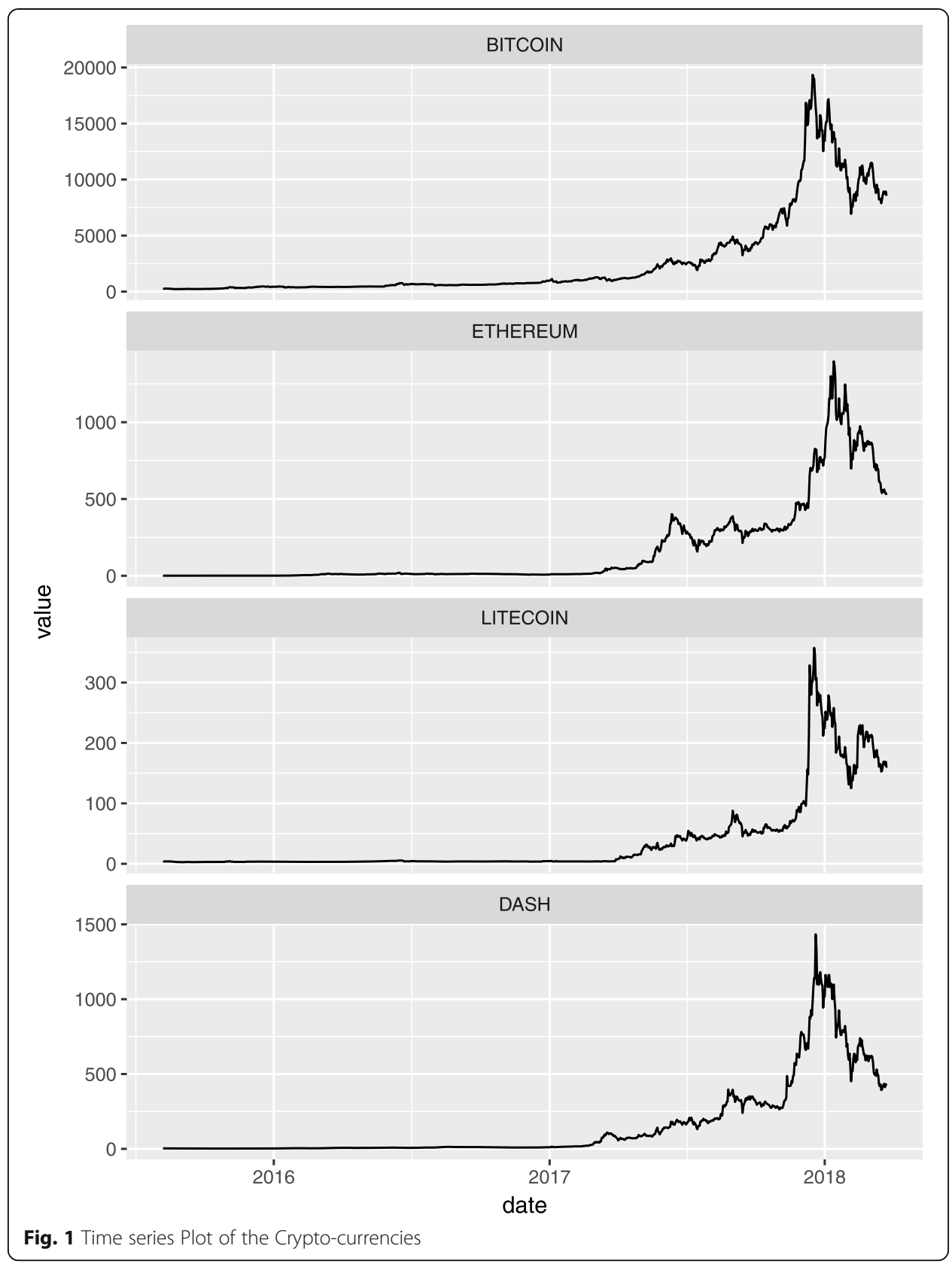

presented in Table 2. If there is a price increase in Bitcoin after the event, we term the event positive and similarly, any event that results in an immediate price decrease is termed as negative event.

From the aforementioned events, we can obtain an outlook about the prevailing moods in the Bitcoin markets during the period of analysis. Our aim is to detect any potential patterns in the crypto-currency co-movements and see if we could relate it with Bitcoin price movements. If the WLMC values decrease with a negative news and increase with a positive news; we can confirm that the market is affected by cryptocurrency price movements. Towards this, we present the WLMC results of estimation; shown in Figs 4, 5, 6 and 7. 


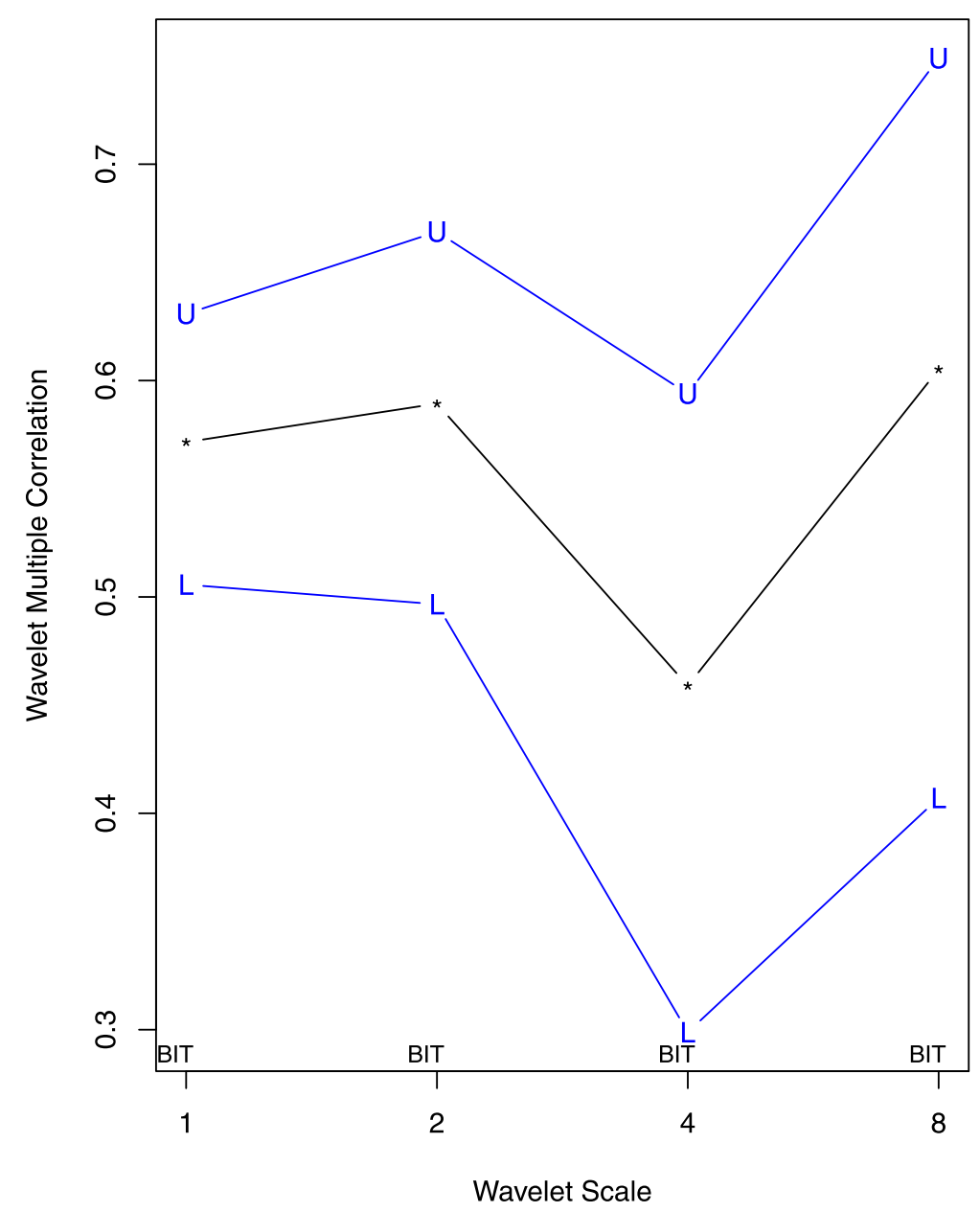

Fig. 2 Wavelet Multiple Correlation of Crypto Currency Prices

Observing the WLMC values across different timescales, we can see a number of common factors. First, the correlation among the markets are high across all the timescales. Second, the nature of the correlation varies in a cyclical fashion, albeit an aperiodic one. Further, the markets record the overall highest correlation values in the initial periods (January-2016). It takes almost 2 years for the market to reach the same peak, and the in-between periods are marred by frequent turbulences. As we proceed from smaller scales (high frequency) to larger scales (low frequency), the cyclical nature of the WLMC is found to be smoothening, implying that the fluctuations prevailing in the crypto-currency co-movement predominantly are of short term nature.

In the following paragraphs, we offer possible explanations behind the cyclical nature of the co-movement. As we identified Bitcoin as the potential market leader with the help of wavelet correlation and cross-correlation analysis, we try to explain the WLMC based on certain events related to Bitcoin prices.

The WLMC values shows a decreasing trend between August to September 2015. During this period, two major events took place in the Bitcoin market. First, arrest of now defunct crypto-exchange Mt. Gox. CEO and then, the announcement of Bitcoin Fork. These two events resulted in a value drop of Bitcoin, only to be picked up during the following months, possibly due to the positive events such as Bitcoin being included into 


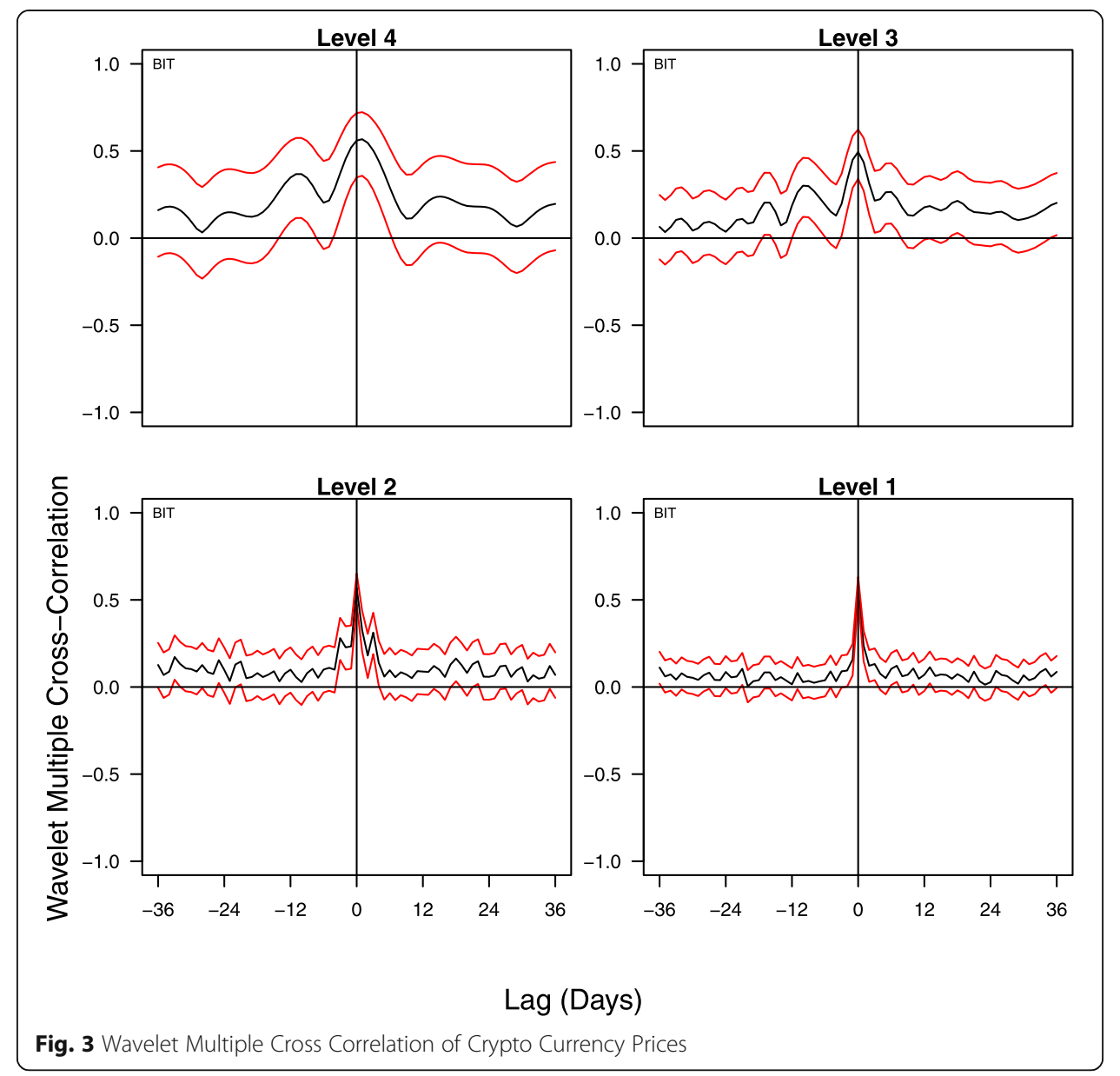

the commodity list in the US, exclusion of Value Added Tax by EU and the Launch of new Crypto-exchange Gemini, offering some sort of Insurance coverage to the investor. The recovery is depicted in the increased value of WLMC across all scales.

In January 2016, major Bitcoin developer Mike Hearn quit Bitcoin, creating a panic in the crypto-currency markets. This was reflected in the bitcoin prices, a drop of around $\$ 35$. Later, the WLMC starts to pick up around April 2016, which coincides with the launch of new Bitcoin related software OpenBazzar, supposed to be a better transaction platform.

In July 2016, the block-rewards of Bitcoins were reduced, as per the bitcoin issue system. This in turn resulted in an initial price rise in Bitcoin. However, the correlation between Bitcoin and other markets drops down immediately. One reason for the said behavior could be that, with the increased difficulty in obtaining Bitcoins, a part of miners and investors would have migrated to other options, resulting in the reduced wavelet correlation values. The correlation reaches its lowest point in August 2016, when the Hong Kong based crypto-currency exchange BitFinex was hacked.

WLMC reaches its peak again in November 2016, something that interestingly coincides with Donald Trump's election as the president of the USA. Around this period, stock-markets, especially that of US showed evidences of capital flight towards assets that are traditionally considered as Safe. A part of such investments has gone into crypto-currencies (Bouoiyour and Selmi 2017), resulting in increased demand and thereby prices. However, this exuberance seems to be short-lived, as we see a sharp 
Table 2 Major Events in the Bitcoin Markets

\begin{tabular}{|c|c|c|c|}
\hline Time Period & Event & $\begin{array}{l}\text { Reaction of Bitcoin Prices } \\
\text { (after } 10 \text { days) }\end{array}$ & Nature \\
\hline August 1, 2015 & $\begin{array}{l}\text { Mark Karpeles, CEO of now defunct } \\
\text { Crypto-Exchange Mt. Gox., arrested in } \\
\text { Japan in allegations of Financial Fraud. }\end{array}$ & $\$ 283.04$ to $\$ 267.09$ & Negative \\
\hline August 15,2015 & $\begin{array}{l}\text { New Fork (software upgrade) named } \\
\text { Bitcoin XT released }\end{array}$ & $\$ 267.34$ to $\$ 214.3$ & Negative \\
\hline September 28,2015 & $\begin{array}{l}\text { Crypto currencies termed as a commodity } \\
\text { by US regulating agency CTFC }\end{array}$ & $\$ 234.65$ to $\$ 238.15$ & Positive \\
\hline October 82,015 & $\begin{array}{l}\text { New Crypto-exchange Gemini launched, } \\
\text { with FIDC insurance }\end{array}$ & $\$ 248.45$ to $\$ 268.01$ & Positive \\
\hline October 22,2015 & EU Declares no VAT on Bitcoin & $\$ 273.82$ to $\$ 318.43$ & Positive \\
\hline October 31,2015 & $\begin{array}{l}\text { Bitcoin article displayed on the front page } \\
\text { of the "Economist" }\end{array}$ & $\$ 323.35$ to $\$ 366.67$ & Positive \\
\hline January 14,2016 & Developer Mike Hearn quits Bitcoin & $\$ 431.76$ to $\$ 397.92$ & Negative \\
\hline April 4, 2016 & $\begin{array}{l}\text { New Decentralized market software } \\
\text { OpenBazzar Launched }\end{array}$ & $\$ 420.61$ to $\$ 426.68$ & Positive \\
\hline July 92,016 & Bitcoin block rewards halved & $\$ 652.14$ to $\$ 674.03$ & Positive \\
\hline August 2, 2016 & Bitfinex hacked, $\$ 72$ million lost & $\$ 594.86$ to $\$ 591.36$ & Negative \\
\hline November 92,016 & Donald Trump elected as US President & $\$ 726.36$ to $\$ 749.1$ & Positive \\
\hline March 10, 2017 & $\begin{array}{l}\text { Winkelwos' crypto-currency ETF application } \\
\text { rejected by the SEC of USA }\end{array}$ & $\$ 1201.86$ to $\$ 1037.85$ & Negative \\
\hline April 1, 2017 & Japan declares Bitcoin as a legal tender & $\$ 1085.03$ to $\$ 1215.69$ & Positive \\
\hline August 1, 2017 & Bitcoin splits into Bitcoin Cash and Bitcoin & $\$ 2787.85$ to $\$ 3383.89$ & Positive \\
\hline September 3, 2017 & China bans ICO for crypto-currencies & $\$ 4668.5$ to $\$ 4223.82$ & Negative \\
\hline September 12,2017 & JP Morgan head calls Bitcoin a fraud & $\$ 4166.59$ to $\$ 3807.07$ & Negative \\
\hline October 25,2017 & New fork in Bitcoin, Bitcoin Gold launched & $\$ 5682.85$ to $\$ 7261.41$ & Positive \\
\hline October 31,2017 & CMIE announces Bitcoin futures & $\$ 6121.79$ to $\$ 7255.21$ & Positive \\
\hline November 82,017 & Proposed fork cancelled & $\$ 7143.47$ to $\$ 7844.44$ & Positive \\
\hline December 11,2017 & CBOE Bitcoin Futures are Launched & $\$ 14,594.78 \$$ to $\$ 17,010.5$ & Positive \\
\hline
\end{tabular}

drop in the correlation values. It coincides with US Securities Exchange Commission's (SEC) rejection of a project on crypto-currency based Exchange-Traded-Fund (ETF), proposed by Winkelwos brothers. However, the correlation picks up after Japan announced the validity of Bitcoin as a legal tender.

However, around August 2017, we see further drop in WLMC values. The reason for the same can be attributed to uncertainty about the potential fork in Bitcoin. In August 2017, the fork resulted in a new crypto-currency namely Bitcoin Cash. Around the same period, Chinese government had initiated a crackdown in crypto-currency markets. As China is one of the major Hub of crypto-currency activities, this crackdown fueled the existing uncertainty, leading to the drop in WLMC values. The market seems to have picked up after the Chinese crackdowns, as evidenced by the increased WLMC values, coinciding with the positive events such as Bitcoin being listed by Cboe Global Markets Inc. and CME Group Inc., and the proposed cancellation of the fork in Bitcoin prices.

As discussed in the introduction part, crypto-currency markets are populated by several new asset in the last couple of years. It would be interesting to see how these assets are moving with respect to the major crypto-currencies in the market. It is our aim to see if they move opposite to the market direction. Towards this, we estimate 


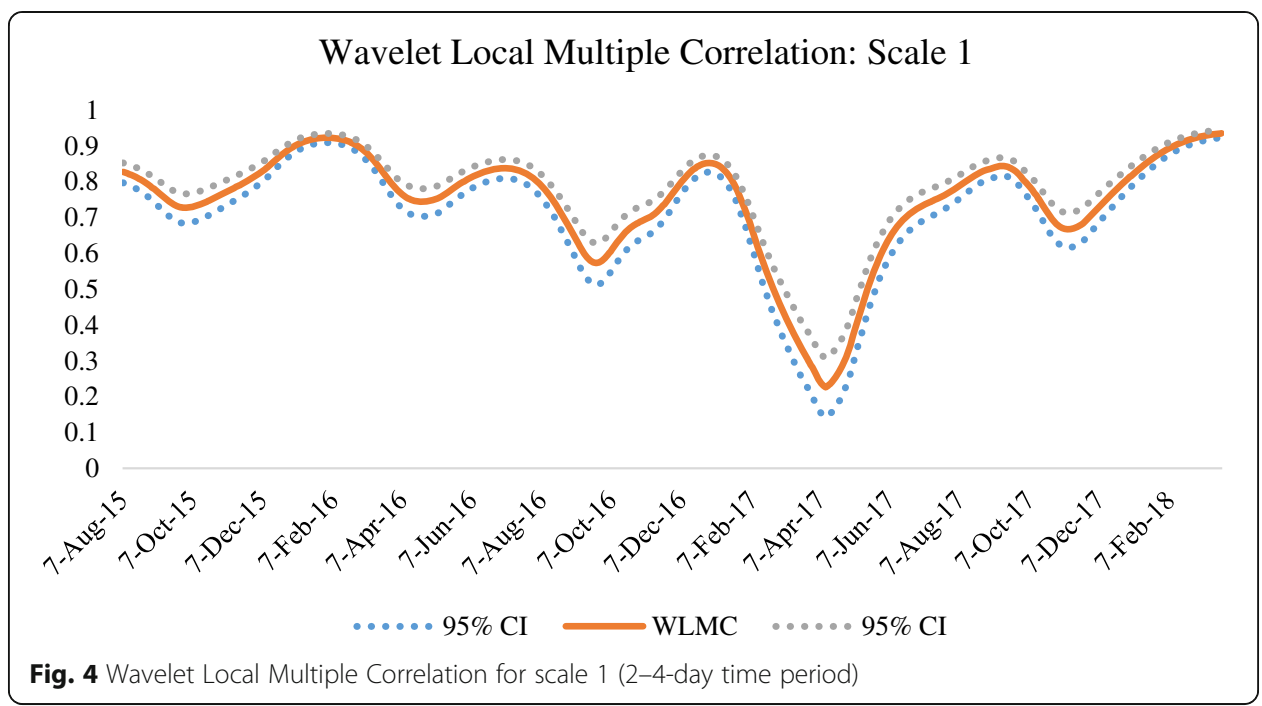

WLMC values for a set of 10 crypto-currency returns. Here we include six additional cryptocurrencies namely Reddcoin, DigixDao, Luckycoin, Bitmark, Edgecoin and Unobatanium. These currencies were picked randomly with varying market capitalization. The result of WLMC estimation is given in Fig. 8.

From the results, it is seen that apart from a fluctuation around the year 2016, the correlation values are around 1. This presents an interesting picture. From the WMC and WMCC results, Bitcoin is identified as the market leader. With a correlation value of 1 persisting for the larger period, it can be said that the market, especially when we consider smaller currencies, follow the fluctuations in the Bitcoin prices always.

From these, it is possible to draw some conclusions about the investor behavior. When there is a price drop in Bitcoins, the correlation structure between Bitcoin and other currencies collapse, indicating that agents distance themselves from cryptoassets. But when Bitcoin is on the upswing, it is reflected in Other crypto-assets as well, cementing Bitcoin's position as the market leader. The fluctuations are frequent during the period of analysis, which is to be expected as crypto-currency markets are still in

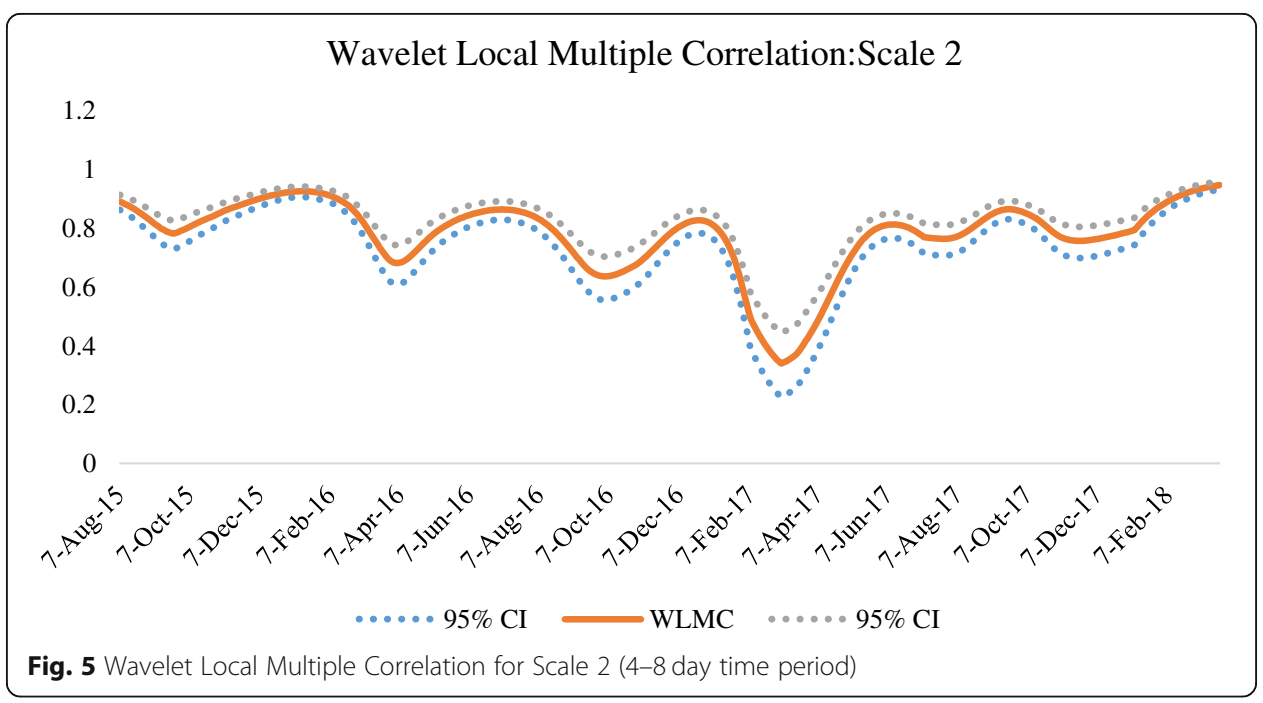




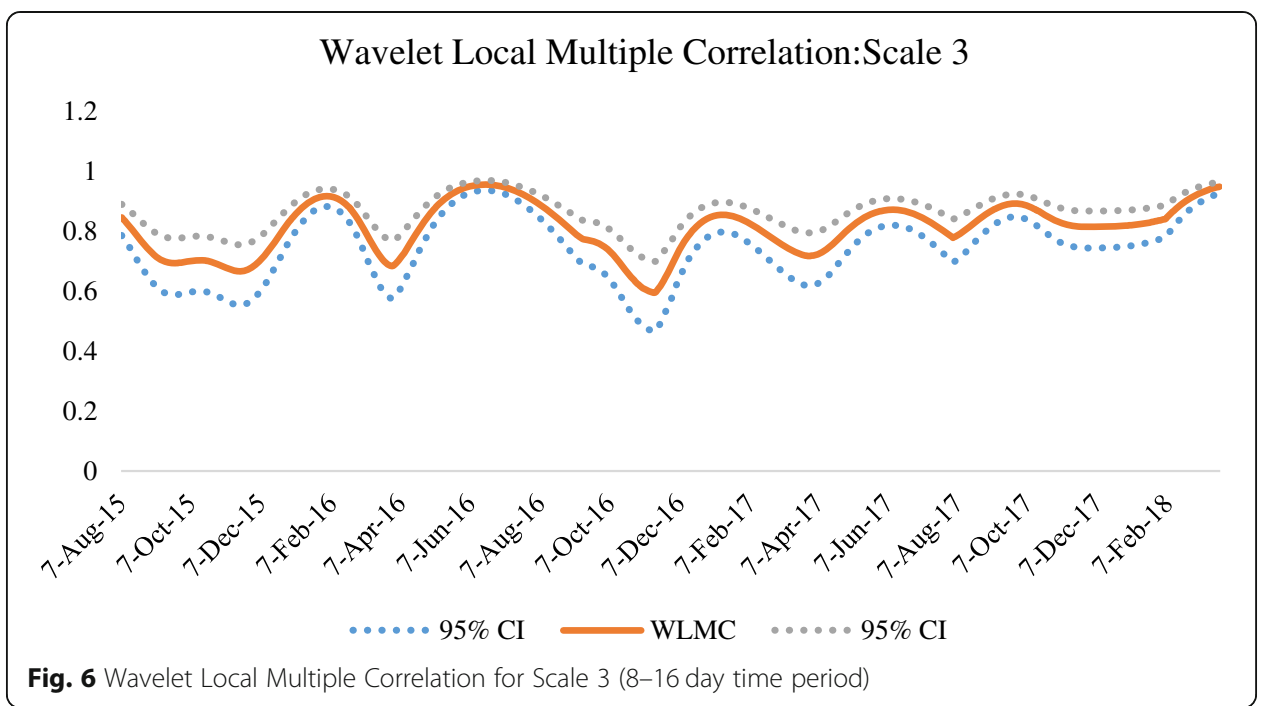

its early stage. It is difficult to comment whether the crypto-currency markets are going to be less volatile in the near future, due to its innate decentralized structure. With crypto-currencies being introduced at par with traditional financial assets, there is a possibility that a better trading and regulatory frame work will come into place. However, it is too early to comment on that and we do not make any assumptions as such.

\section{Concluding remarks}

We studied the time varying co-movement patterns of the crypto-currency markets with the help of wavelet-based methods. Daily bilateral exchange rate of four major cryptocurrencies namely Bitcoin, Ethereum, Lite and Dashcoin from 7 August, 2015 to 24 March, 2018 were used for the analysis. First, we identified Bitcoin as potential market leader using Wavelet multiple correlation and cross correlation. Next, we estimated Wavelet Local Multiple Correlation for the given crypto-currency prices. From the results, we could observe that the correlation follows an aperiodic cyclical nature, and the crypto-currency

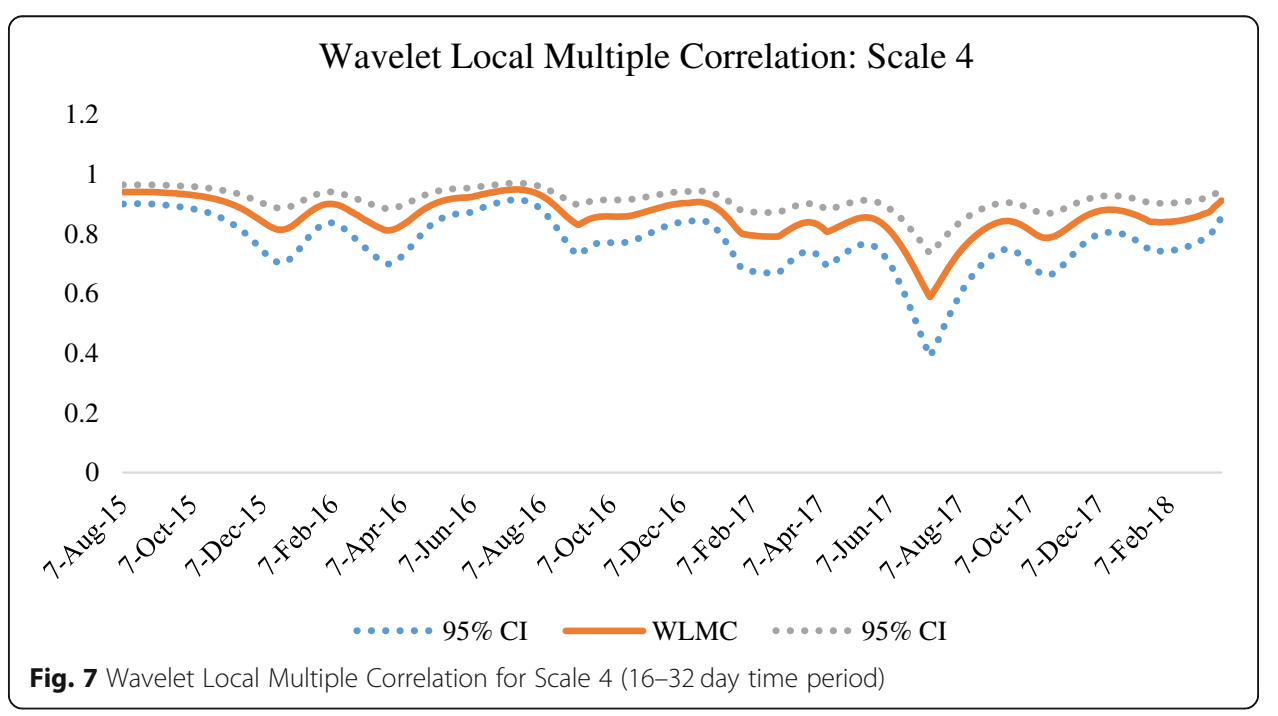




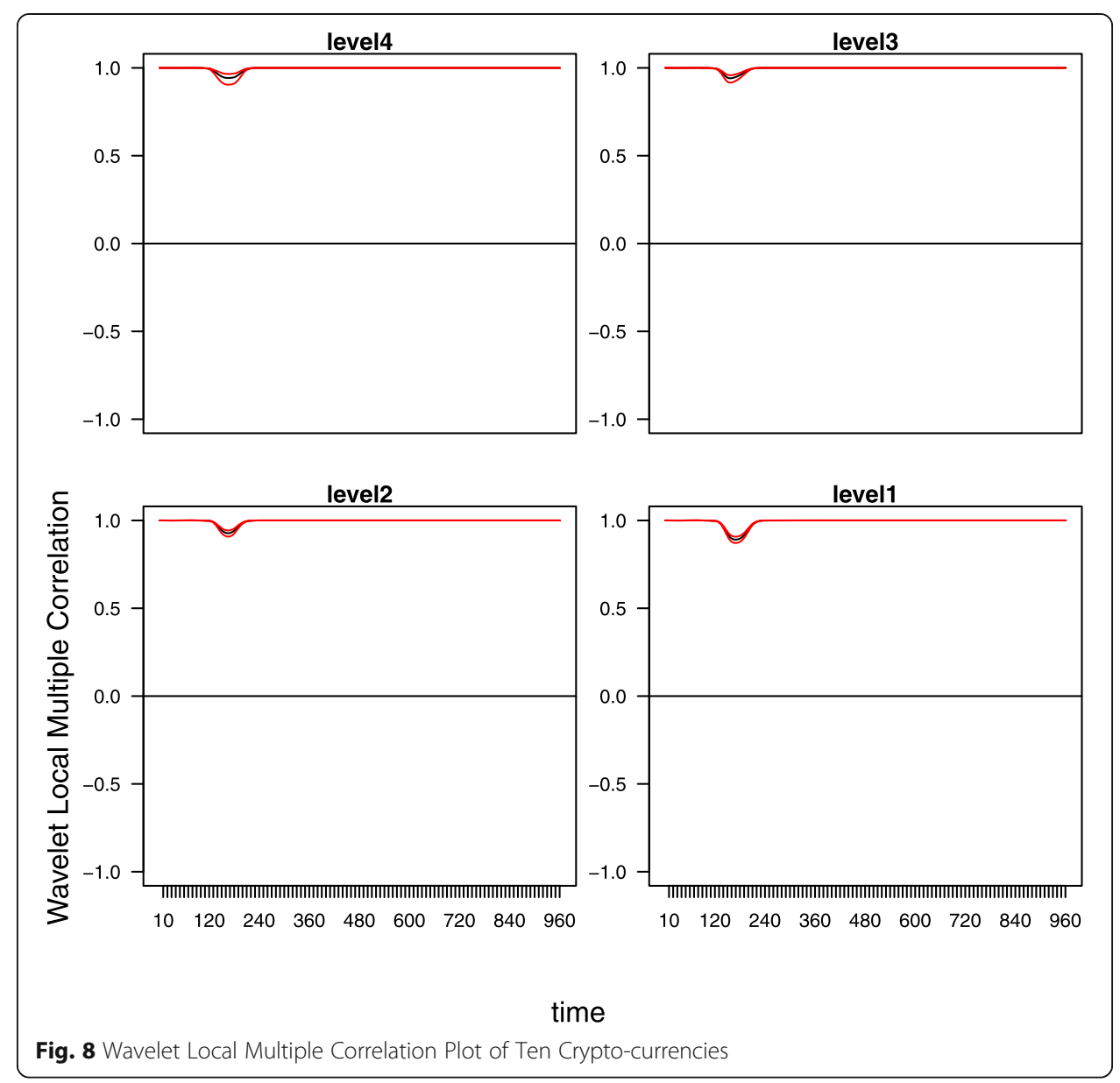

prices are influenced by Bitcoin price movements. The demand for crypto- assets increases when Bitcoin prices are on the rise, resulting in a price rise in other crypto-currencies. Conversely, any price drop in Bitcoin is immediately reflected in other crypto-currency prices.

From an investor perspective, this coupling of other crypto-currencies with Bitcoin creates a dilemma. While crypto-currency assets can possibility act as instruments of hedge in a traditional portfolio, along with other assets such as equities and bonds, we do not suggest constructing a portfolio entirely composed of Crypto-assets. From the evidences obtained from the analysis, constructing a portfolio based on cryptocurrencies may be risky at this point of time as the alt-coin prices are mainly driven by Bitcoin prices, and any shocks in the latter is immediately transmitted to the former. Even by looking at the skewed market capitalization in the crypto-currency market; with Bitcoin occupying almost 50\% of the total market capitalization, it would not be prudent to construct a portfolio that entirely consists of crypto-currency assets.

\section{Appendix}

\section{Relationship between $r^{2}$ and $R^{2}$}

Let us consider the following where $\mathrm{y}$ is the actual series, $\hat{y}$ is the fitted series and $\mathrm{e}$ is the residual. $R^{2}$ is defined as the coefficient of determination. $R^{2}=\frac{\operatorname{var}(\hat{y})}{\operatorname{var}(y)}$

$$
\text { Let } y=\hat{y}+e
$$


$\operatorname{Cov}[\hat{y}, e]=0$

$\operatorname{Cov}(x,(y+Z))=\operatorname{Cov}(x, y)+\operatorname{Cov}(x, Z)$

$\operatorname{Var}(x)=\operatorname{Cov}(x, x)$

$\operatorname{Var}(x)=1 / n \sum_{i=1}^{n}\left(x_{i}-\bar{x}\right)^{2}$

$r_{y, \hat{y}}=\frac{\operatorname{Cov}(y, \hat{y})}{\sqrt{\operatorname{var}(y) \operatorname{var}(\hat{y})}}$ where $\mathrm{r}$ is the Person correlation coefficient

Now

$$
\begin{aligned}
& r_{y, \hat{y}}^{2}=\left(\frac{\operatorname{Cov}(y, \hat{y})}{\sqrt{\operatorname{var}(y) \operatorname{var}(\hat{y})}}\right)^{2} \\
& r_{y, \hat{y}}^{2}=\frac{\operatorname{Cov}(y, \hat{y})}{\sqrt{\operatorname{var}(y) \operatorname{var}(\hat{y})}} \frac{\operatorname{Cov}(y, \hat{y})}{\sqrt{\operatorname{var}(y) \operatorname{var}(\hat{y})}} \\
& r_{y, \hat{y}}^{2}=\frac{\operatorname{Cov}(y, \hat{y}) \operatorname{Cov}(y, \hat{y})}{\operatorname{var}(y) \operatorname{var}(\hat{y})} \\
& r_{y, \hat{y}}^{2}=\frac{\operatorname{Cov}(\hat{y}+e, \hat{y}) \operatorname{Cov}(\hat{y}+e, \hat{y})}{\operatorname{var}(y) \operatorname{var}(\hat{y})} \\
& r_{y, \hat{y}}^{2}=\frac{(\operatorname{Cov}(\hat{y}, e)+\operatorname{Cov}(\hat{y}, \hat{y}))(\operatorname{Cov}(\hat{y}, e)+\operatorname{Cov}(\hat{y}, \hat{y}))}{\operatorname{var}(y) \operatorname{var}(\hat{y})} \\
& r_{y, \hat{y}}^{2}=\frac{\operatorname{Cov}(\hat{y}, \hat{y}) \operatorname{Cov}(\hat{y}, \hat{y})}{\operatorname{var}(y) \operatorname{var}(\hat{y})} \\
& r_{y, \hat{y}}^{2}=\frac{\operatorname{var}(\hat{y}) \operatorname{var}(\hat{y})}{\operatorname{var}(y) \operatorname{var}(\hat{y})} \\
& r_{y, \hat{y}}^{2}=\frac{\operatorname{var}(\hat{y})}{\operatorname{var}(y)}=\frac{1 / n \sum_{i=1}^{n}\left(y_{i}-\bar{y}\right)^{2}}{1 / n \sum_{i=1}^{n}\left(y_{i}-\bar{y}\right)^{2}}=\frac{E S S}{\operatorname{TSS}}=R^{2}
\end{aligned}
$$

\section{Abbreviations}

ARDL: Autoregressive Distributed Lag; MODWT: Maximal overlap discrete wavelet transform; OTC: Over-the-Counter; WLMC: Wavelet Local multiple correlation; WMC: Wavelet multiple correlation; WMCC: Wavelet multiple crosscorrelation

\section{Acknowledgements}

We thank the Editor and anonymous reviewers for helpful comments.

\section{Authors' contributions}

Both the authors contributed equally and approved the manuscript submission.

\section{Funding}

Not Applicable

\section{Availability of data and materials}

The datasets used for estimation is obtained from Coin Market Cap [https://coinmarketcap.com/]

\section{Competing interests}

The authors declare that they have no competing interests. 


\section{Author details}

'Waggle Lab, University of Kerala, Karyavattom, Thiruvananthapuram, Kerala 695581, India. ${ }^{2}$ School of Economics, Narsee Monjee Institute of Management Studies, Bangalore, Karnataka 560083, India.

\section{Received: 27 August 2018 Accepted: 30 May 2019}

\section{Published online: 12 July 2019}

\section{References}

Ali R, Barrdear J, Clews R, Southgate J (2014) The economics of digital currencies. Bank England Q Bull 54(3):276-286

Baek C, Elbeck M (2015) Bitcoins as an investment or speculative vehicle? A first look. Appl Econ Lett 22(1):30-34

Baur DG, Hong K, Lee AD (2018) Bitcoin: medium of exchange or speculative assets? J Int Financ Mark Inst Money 54:177-189

Blau BM (2017) Price dynamics and speculative trading in bitcoin. Res Int Bus Financ 41:493-499

Bohme R, Chirstin N, Edelman B (2015) Bitcoin: economics, technology, and governance. J Econ Perspect 29(2):213-238

Bouoiyour J, Selmi R (2016) Bitcoin: a beginning of a new phase. Econ Bull 36(3):1430-1440

Bouoiyour, J., \& Selmi, R. (2017). Are trump and bitcoin good partners?. arXiv preprint arXiv:1703.00308

Bouoiyour J, Selmi R, Tiwari AK, Olayeni OR (2016) What drives bitcoin price. Econ Bull 36(2):843-850

Catania L, Stefano G, Francesco R (2019) Forecasting cryptocurrencies under model and parameter instability. Int J Forecast 35(2):485-501

Cheah ET, Fry J (2015) Speculative bubbles in bitcoin markets? An empirical investigation into the fundamental value of bitcoin. Econ Lett 130:32-36

Cheung A, Roca E, Su JJ (2015) Crypto-currency bubbles: an application of the Phillips-Shi-Yu (2013) methodology on Mt. Gox bitcoin prices. Appl Econ 47(23):2348-2358

Chu J, Nadarajah S, Chan S (2015) Statistical analysis of the exchange rate of bitcoin. PLoS One 10(7):e0133678. https://doi. org/10.1371/journal.pone.0133678

Ciaian P, Rajcaniova M (2018) Virtual relationships: short-and long-run evidence from bitcoin and altcoin markets. J Int Financ Mark Inst Money 52:173-195

Ciaian P, Rajcaniova M, Kancs DA (2016) The economics of bitcoin price formation. Appl Econ 48(19):1799-1815

Delfin-Vidal R, Romero-Meléndez G (2016) The fractal nature of bitcoin: evidence from wavelet power spectra. In: Trends in mathematical economics. Springer, Cham, pp 73-98

Dirican C, Canoz I (2017) The cointegration relationship between bitcoin prices and major world stock indices: an analysis with ARDL model approach. J Econ Financ Acc 4(4):377-392

Dwyer GP (2015) The economics of bitcoin and similar private digital currencies. J Financ Stab 17:81-91

Dyhrberg AH (2016) Bitcoin, gold and the dollar-a GARCH volatility analysis. Financ Res Lett 16:85-92

Fernández-Macho, J. (2018). Time-localized wavelet multiple regression and correlation. Physica A: Statistical Mechanics and its Applications, 492:1226-1238.

Fisher RA (1922) On the mathematical foundations of theoretical statistics. Philos Trans R Soc Lond A 222:309-368

Fry J, Cheah ET (2016) Negative bubbles and shocks in cryptocurrency markets. Int Rev Financ Anal 47:343-352

Gandal N, Hamrick JT, Moore T, Oberman T (2018) Price manipulation in the bitcoin ecosystem. J Monet Econ 95:86-96

Glaser F, Zimmermann K, Haferkorn M, Weber MC, Siering M (2014) Bitcoin - asset or currency? Revealing users' hidden intentions. In: Proceedings of the European Conference on Information Systems (ECIS). Association for Information Systems, Tel Aviv

Godsiff P (2015) Bitcoin: bubble or Blockchain. In: Jezic G, Howlett R, Jain L (eds) Agent and multi-agent systems: technologies and applications. Smart innovation, systems and technologies, vol 38. Springer, Cham

Henriques I, Sadorsky P (2018) Can bitcoin replace gold in an investment portfolio? J Risk Financ Manage 11:48

Hotz-Behofsits C, Florian H, Thomas OZ (2018) Predicting crypto-currencies using sparse non-Gaussian state space models. J Forecast 37(6):627-640

Jiang Y, Nie H, Ruan W (2017) Time-varying long-term memory in bitcoin market. Financ Res Lett 25:280-284

Johansen S (1992) Determination of co-integration rank in the presence of a linear trend. Oxf Bull Econ Stat 54:383-397

Katsiampa P (2017) Volatility estimation for bitcoin: a comparison of GARCH models. Econ Lett 158:3-6

Khaled G, Samir S, llyes A, Zied F (2018) Portfolio diversification with virtual currency: evidence from bitcoin. Int Rev Financ Anal. https://doi.org/10.1016/j.irfa.2018.03.004

Kristoufek $L$ (2015) What are the main drivers of the bitcoin price? Evidence from wavelet coherence analysis. PLoS One. https://doi.org/10.1371/journal.pone.0123923

Macho JF (2012) Wavelet multiple correlation and cross-correlation: a multiscale analysis of eurozone stock markets. Physica A 391:1097-1104

Macho JF (2018) Time-localized wavelet multiple regression and correlation. Physica A 492:1226-1238

Moser M, Bohme R, Breuker D (2013) An inquiry into money laundering tools in the Bitcoin ecosystem. In: eCrime Researchers Summit (eCRS), 2013. IEEE, San Francisco pp 1-14

Nadarajah S, Chu J (2017) On the inefficiency of bitcoin. Econ Lett 150:6-9

Narayanan A, Bonneau J, Felten E, Miller A, Goldfeder S (2016) Bitcoin and cryptocurrency technologies: a comprehensive introduction. Princeton University Press, Princeton

Pieters G, Vivanco S (2017) Financial regulations and price inconsistencies across bitcoin markets. Inf Econ Policy 39:1-14

Salman A, Razzaq MGA (2018) Bitcoin and the world of digital currencies. In: Financial Management from an Emerging Market Perspective. InTech. https://doi.org/10.5772/intechopen.71294

Smith C, Kumar A (2018) Crypto-currencies - an introduction to not-so-funny moneys. J Econ Surv. https://doi.org/10.1111/joes.12289

Tony K, Hien PT, Thomas W (2018) Bitcoin is not the new gold - a comparison of volatility, correlation, and portfolio performance. Int Rev Financ Anal 59:105-116 
Urquhart A (2016) The inefficiency of bitcoin. Econ Lett 148:80-82

Urquhart A (2017) Price clustering in bitcoin. Econ Lett 159:145-148

Urquhart A (2018) What causes the attention of bitcoin? Econ Lett 166:40-44

Van Alstyne M (2014) Why bitcoin has value. Commun ACM 57(5):30-32

White LH (2015) The market for cryptocurrencies. Cato J 35(2):383-402

Yermack D (2013) Is bitcoin a real currency? An economic appraisal. In: NBER Working Paper No 19747

Zhu Y, Dickinson D, Li J (2017) Analysis on the influence factors of Bitcoin's price based on VEC model. Financ Innov 3:3. https://doi.org/10.1186/s40854-017-0054-0

\section{Publisher's Note}

Springer Nature remains neutral with regard to jurisdictional claims in published maps and institutional affiliations.

Submit your manuscript to a SpringerOpen ${ }^{\circ}$ journal and benefit from:

- Convenient online submission

- Rigorous peer review

- Open access: articles freely available online

- High visibility within the field

- Retaining the copyright to your article

Submit your next manuscript at $\boldsymbol{\nabla}$ springeropen.com 